NBER WORKING PAPER SERIES

DYNAMIC BEHAVIOR OF IMPERFECTLY COMPETITIVE ECONOMIES

WITH MULTIPLE EQUILIBRIA

Russe11 Cooper

Working Paper No. 2388

NATIONAL BUREAU OF ECONOMIC RESEARCH

1050 Massachusetts Avenue

Cambridge, MA 02138

September 1987

Discussions with John Bigelow, John Haltiwanger, Andrew John, Boyan Jovanovic, Doug McManus and Walter Heller at various stages in this research are greatly appreciated. Remaining errors and misinterpretations are my own responsibility. Financial assistance under NSF SES-8605302 is gratefully acknowledged. The research reported here is part of the NBER's research program in Economic Fluctuations. Any opinions expressed are those of the author and not those of the National Bureau of Economic Research. 


\author{
Dynamic Behavior of Imperfectly Competitive \\ Economies with Multiple Equilibria
}

\begin{abstract}
This paper investigates the dynamic behavior of an economy with multiple Nash equilibria. The first part of the paper analyzes an abstract game exhibiting multiple equilibria. A history dependent selection criterion is proposed which induces correlated behavior in equilibrium even though agents are playing one-shot games and disturbances are not correlated over time.

The second part of the paper investigates a specific model of multiple equilibria. Here the multiplicity is induced by the presence of a discrete decision on the part of firms regarding their choice of technique. The implications of the selection criterion introduced in the first part of the paper are illustrated through this example. Again correlated behavior emerges in a sequence of independent one-shot games. The model economy may also experience prolonged periods in which a low productivity technology is in use and then, as a consequence of a large real disturbance, may switch to an alternative equilibrium in which a high productivity technology is utilized. The paper also discusses the Pareto ordering of these equilibria.
\end{abstract}

Russe11 Cooper Hoover Institution Stanford University Stanford, CA 94305 
I. Introduction

Formalization of the Keynesian notion of coordination failures has led to the design of model economies with multiple Nash equilibria which are Pareto rankable. In the presence of multiple Nash equilibria, the economy can become "stuck" at an equilibrium which is Pareto dominated by another equilibrium. Yet, agents have no reason to alter their behavior since their actions are best responses to the actions of other players.

Coordination failures of this type are not possible in a Walrasian model with perfectly competitive markets and flexible wages and prices. They emerge in models which limit the coordinating powers of the auctioneer by either fixing some prices, allowing imperfect competition or postulating a technology for matching traders.

Model economies displaying this coordination failure property were exhibited by Diamond [1982], Heller [1986], Howitt [1985], Kiyotaki [1985], Roberts [1984,1986] and Cooper-John [1986]. Diamond's results derive from a model in which markets are replaced by a random matching mechanism. Agents perceive that their chances of trading depends on the number of other agents producing in any period. Hence, many conjectures on the number of other agents producing in a given period can be fulfilled in equilibrium. Many times, there is one equilibrium with low output and employment which is Pareto dominated by another with high output and employment. Howitt introduces costs of trading which depend on the level of activity in the economy to generate similar results.

The other papers introduce imperfect competition into a multi-sector economy. The feedback effects between agents are then brought about by the normality of consumption goods in demand functions. Heller [1986] shows that 
one can construct economies with multiple equilibria by varying the properties of demand functions. The results reported by Kiyotaki and CooperJohn place emphasis on the importance of technological factors in generating multiple equilibria. As in Diamond's model, these equilibria can be Pareto ranked by the level of economic activity. Cooper-John also discusses the connection between these models of imperfect competition and Diamond's model of search.

One of the potential drawbacks to this line of inquiry is that the presence of multiple equilibria weakens the predictive power of these models. In particular, conditions for the existence of multiple equilibria, do not provide insights into which of the equilibria is more or less likely to be observed. In fact, it is often argued that the Pareto dominant equilibrium provides a natural focal point and hence is likely to be the outcome of a game with multiple Nash equilibria. Acceptance of this claim invalidates multiple equilibrium theories of coordination failures.

This paper discusses an approach to selecting an equilibrium allocation which does not rest on the presumption that the Pareto optimal equilibrium is a focal point. ${ }^{1}$ The argument advanced here is that historical experience generates a focal point. If the economy has been at a particular equilibrium in the past, then as the fundamental characteristics of the economy change, the new equilibrium is likely to be near the old one. More generally, as the economy varies due to small disturbances, it is natural to think that the equilibrium outcomes will respond by moving to an equilibrium which is "close." Using techniques of regular economies (discussed below), there will generically exist equilibria close to a given equilibrium point for small disturbances to the economy. Thus, generically, one can perform these local 
comparative statics and apply this selection criterion.

This intuition is made specific in the context of a general model of strategic interactions. A selection hypothesis is advanced to determine the equilibrium from the set of equilibria. When this hypothesis is used to select among equilibria, the path of the economy is dependent on historical experience. This general approach is discussed in section II.

Using a variant of the multiple equilibrium example proposed in CooperJohn, this paper traces the implications of this selection hypothesis for the observed time series of this economy. The results imply that correlated output movements can be generated using this selection criterion even though individuals in the economy are playing one-shot games and the shocks to the economy are uncorrelated over time. In this environment, it is also shown that small changes in "policy variables" may have large effects as the economy passes through a critical point. That is, policy (interpreted as a variation of the parameters of the game) may have "catastrophic effects."

In addition to being useful for exhibiting this selection criterion, the example analyzed in Section III may be interesting in its own right as a source of multiplicity. The example rests on firms choosing both a production technology (or the number of plants to operate) and the level of output. The introduction of this discrete technology choice is the source of the multiplicity and the basis for the inertial behavior.

\section{A General Approach}

To provide a framework for the analysis, consider a game between I identical agents indexed by $i=1,2, \ldots$. I. Each agent selects a variable, $e_{i}$, to maximize $U\left(e_{i}, e_{-i}, \tau\right)$ where $e_{-i}$ refers to the vector of actions taken by the other agents, $r \in \Gamma$ is an index of the game that these agents are playing 
and $\Gamma$ is the set of possible games. Assume that $U()$ is continuously differentiable and concave in $e_{i}$. Suppose that $e_{i} \in[0, W]$ where $0<W \in \Re$ is the largest feasible action for agent $i$. Thus the strategy space is compact and convex. When agent $i$ selects action $e_{i}$ and $e_{j}=e$ for $j \neq i$, the utility of agent $i$ is denoted $U\left(e_{i}, e, \tau\right)$. The function $\phi(e, \tau)$ is the utility maximizing choice of agent $i$ if all other agents select action $e$ in the game $\tau$. That is,

$\frac{\partial U\left(e_{i}, e, \tau\right)}{\partial e_{i}}=0$ at $e_{i}=\phi(e, \tau)$.

The set of Nash equilibria for the game $\tau$ is $E(\tau)$ where

$E(\tau)=\{\mathrm{e} \mid \phi(\mathrm{e}, \tau)=\mathrm{e}\}$

Our interest is in the relationship between $\tau$ and the set $E(\tau)$. For that analysis, the techniques of global analysis of smooth economies will be quite useful. To use these techniques, it is necessary to assume U() is continuously differentiable. The continuous differentiability of payoffs is an assumption often made in this literature and can be defended by noting that in the space of preferences, for any utility function not satisfying this assumption, there will exist a utility function which is continuously differentiable "close by". The assumption that the strategy space is an interval ensures that the techniques for smooth economies can be used in this analysis.

These assumptions will allow us to explore the properties of $E(\tau)$. First, does there exist an equilibrium? The set $E(\tau)$ will be non-empty for all $r$ if 
$\lim _{\mathrm{e} \rightarrow \mathrm{f}} \phi(\mathrm{e}, \tau)>0$ and $\underset{\mathrm{e} \rightarrow \mathrm{W}}{\lim } \Phi(\mathrm{e}, \tau)<\mathrm{W}$.

These restrictions imply that if all other agents in the economy choose values of e close to 0 , then the best response of the remaining agent will be to provide a positive level of effort. If all other agents select a level of effort close to $\mathrm{W}$, the best response of the remaining agent is to produce less. These conditions, which are analogous to the boundary assumptions used in competitive analysis, along with the continuity and curvature assumptions on $\mathrm{U}()$ will imply the existence of an interior symmetric Nash equilibrium. (Hence we can work with the open strategy space of $(0, W)$ ).

There may, in fact, be multiple equilibria for some $\tau$. A necessary condition for multiple symmetric Nash equilibria is for $\phi(e, \tau)$ to be increasing in e for a given $\tau$. That is, if all other agents provide more effort, it is in the interest of the remaining agent to supply more effort as well. This is the condition called strategic complementarity in BulowGeanokoplos-Klemperer [1985] and used extensively in Cooper-John [1986] .

To understand the correspondence $E(\tau)$, Figure 1 provides a heuristic graph of $E(\tau) X \Gamma$. This is often termed the equilibrium manifold in the literature on smooth economies. Any point on the manifold represents a combination of a game $\tau$ and a level of effort, $e \in(0, W)$, for all agents such that $e \in E(\tau)$. The projection from the equilibrium manifold to $\Gamma$ is often termed the Debreu mapping.

There are a number of important properties of the equilibrium manifold worth noting. First, for all $\tau$ except $\tau_{1}$ and $\tau_{2}$, the set of equilibria contains an odd number of elements. The games $\tau_{1}$ and $\tau_{2}$ are called critical 
games. The likelihood that the economy would ever be at such a game is zero. Call games that are not critical, regular. Second, note that the number of equilibria is constant in the neighborhood of a regular game. This second property is derived from applying the inverse function theorem to the Debreu mapping. Third, for a regular game $\tau *$, there will exist $k$ continuously differentiable functions such that the equilibria of any game $\tau$ in the neighborhood of $\tau^{*}$ are given by these functions evaluated at $\tau$. The second and third properties are stated formally in Debreu [1970]. For fairly general games, Van Damme [1983] provides a proof that (i) Nash equilibria are regular for almost all normal form games (ii) that the regular equilibria are locally unique and (iii) the number of equilibria is odd.

For a regular game, these properties imply a type of a local comparative statics result in that it is possible to alter the game a little around a regular game and obtain a prediction about the outcome in the new game given the equilibrium in the original game. That is, if $e$ is the symmetric Nash equilibrium for game $\tau$, then the equilibrium $e^{\prime}$ would be the equilibrium selected for game $\tau^{\prime}$ in Figure 2 .

This local comparative statics result implies a selection criterion which is history dependent. That is, it specifies a process for selecting an equilibrium out of $E(\tau)$ which depends on the history of the game. This process seems quite reasonable and desirable since one would imagine that small variations in the characteristics of an economy would not alter the equilibrium prediction very much.

The analysis which follows is an attempt to look at the dynamics of an economy (or game) in which this local comparative statics property is employed as a selection device. That is, consider a sequence of one shot 
games where the game that is actually chosen in period $t,{ }^{t}{ }$, is random. Then given a criterion for selecting $\mathbf{e}_{t} \in E\left(\tau_{t}\right)$, the distribution over $\Gamma$ will induce a distribution over the set of equilibria. Our interest is in understanding the properties of this mapping and its relation to our proposed selection criterion.

The selection criterion extends the intuition for the local comparative statics result to more general variations in the game. For small variations in $\tau$, if $\tau_{t}$ is in the neighborhood of $\tau_{t+1}$ then $e_{t+1} \in E\left(\tau_{t+1}\right)$ will be in the neighborhood of $\mathrm{e}_{t} \in E\left(\tau_{t}\right)$. So once we know $\mathrm{e}_{t}$, this criterion predicts an equilibrium in period $t+1$ for $\tau_{t+1}$ close to $\tau_{t}$. $\quad$ For larger variations in $\tau$, this local selection criterion needs to be extended. We say that two equilibria are on the same path if there is a continuous selection out of the equilibrium correspondence connecting them. So, in considering two games, if $e_{t}$ is the equilibrium for $\tau_{t}$, and $e_{t+1} \in \tau+t$ and there is a path connecting $e_{t}$ and $e_{t+1}$, then $e_{t+1}$ will be the equilibrium outcome for $\tau_{t+1}$. Thus $\tau_{t}$ and $\tau_{t+1}$ need not be close to one another in order to employ this selection criterion.

This proposed criterion rests on a number of arguments advanced in the literature. First, the local comparative statics results noted above seem quite reasonable so that for sufficiently small variations in $r$, the solution should move locally. This effect alone generates some history dependence in the outcome through the effect of historical experience on the conjectures agents hold about the behavior of others in the game.

Second, the tracing procedure advocated by Harsanyi [1975] would support this selection criterion as well. The tracing procedure starts by specifying priors for each players about the strategies of other players. The best 
responses by players for these priors provides an initial vector of actions. The tracing procedure then selects an equilibrium by moving along a path from this initial vector of actions to the set of equilibria for the given game as the weight agents place on their initial priors decreases. According to Harsanyi, this process occurs through introspection on the part of the players. In our setting, the equilibrium in the previous period would provide the starting point for the tracing procedure which would then select an equilibrium along the path.

Third, one could rationalize (a variant of) this selection process through a local stability argument. ${ }^{2}$ As discussed by Furth [1986] in the context of oligopoly models, one can specify a simple dynamical system which describes changes in the actions of the players as a function of the vector of strategies chosen by all players. This is taken to describe the adjustment process of agents out of equilibrium. Using this approach, the selection criterion proposed above can be interpreted as stating that the economy moves along a path linking locally stable equilibria. So, as long as the analysis begins with an economy on a locally stable branch of the equilibrium manifold, as the game varies, the equilibrium will simply move along that same branch.

Finally, suppose that in the economy there exists a group of agents who behaved in a non-responsive manner or inertial manner in that they did not vary decisions for small changes in the environment (see the discussion in Akerlof-Yellen [1985] and Haltiwanger-Waldman [1985]). In the presence of these agents, other, more responsive, agents in the game will be led to conjecture that the economy will not vary much in the presence of shocks and this will support the selection criterion advocated in this paper. This will 
hold even as the proportion of "inertial" agents becomes small.

For sufficiently large changes in $r$, the set of equilibria may change dramatically and branches may disappear. In this case, the economy has undergone a catastrophe in that the game has passed through a critical point and the selection criterion proposed above may not give a precise prediction. In Figure 2, if the economy goes from $r$ to $r^{\prime}$ then the selection criterion will select $\mathrm{e}^{\prime}$. However, if the economy goes from $r$ to $r$, the equilibrium is not determined by our selection criterion since there is no path linking e to any $e \in E\left(\tau^{\prime \prime}\right)$. In this event, a jump in the economy will occur and we are without a precise prediction about the outcome.

The selection criterion proposed here generates a stochastic difference equation to specify the equilibrium outcome. Since history provides a focal point in selecting the equilibrium, the outcomes in this economy will exhibit some serial correlation. How are the initial conditions for this equation specified? These conditions are determined by periods in which the economy has a unique outcome. So, in Figure 1 , if the economy is to the "left" of $\tau_{1}$ or to the "right" of $\tau_{2}$, there is an unique prediction. When $r$ lies between these two critical games, then the equilibrium prediction depends on the equilibrium that was selected in the previous play of the game.

Finally, it should be noted that one can interpret variations in $r$ as a consequence of policy actions by a government which moves before the agents in the economy. I.e. the government picks the game that the private agents subsequently play. The effects of "policy" on this economy depends on whether the policy alters the economy locally or causes a catastrophe. So small variations in policy variables will alter the equilibrium outcome a little while large policy changes can cause dramatic effects on allocations. 
Thus characterizing policy effects from local measures of agents decisions rules will be helpful only as guidance on the effects of small policy changes.

III. Multiple Equilibria and the Choice of Technique

To make this discussion a bit more concrete, this section analyzes a simple production economy exhibiting multiple equilibria and uses this structure to display some of the time series properties noted above. The multiplicity of equilibria in this example is related to that in Cooper-John [1986] in that firms have a choice of production techniques which differ by their fixed and marginal costs. In Cooper-John, this was interpreted as a choice of the number of shifts to run a plant. As in Kiyotaki as well, the multiplicity studied here derives from technological features as opposed to the structure of demands utilized in Heller.

Consider an economy with three traded commodities. Two of these commodities are produced by firms and the third is endowed to a group of agents termed outsiders. These outsiders have an aggregate endowment of $2 \overline{\mathrm{M}}$ which is spent equally on each of the two produced goods. In what follows, variations in $\bar{M}$ will be the source of fluctuations in this economy.

Assume that there are $F$ firms in each of two sectors, indexed $i=1,2$ producing the two other commodities. The number of firms is taken as given and is assumed to be finite so that the quantity decisions of firms have nonnegligible effects on the prices in their sectors of activity.

Firms in sector 1 are assumed to be consumers of sector 2 output and the non-produced good. For simplicity, assume that these firms have CobbDouglas preferences over these two commodities with the budget share of sector 2 output being $\alpha$. Their preferences over consumption and labor time 
are given by

$$
c_{2}^{\alpha} m^{(1-\alpha)}-\mathrm{n}
$$

Here $\mathrm{n}$ denotes time spent at work and this must be less than or equal to the time endowment of these agents. In the analysis that follows we will ignore this constraint and focus on interior equilibria.

Sector 1 firms select both a level of output and a technology. In particular, suppose that firms choose between two techniques having associated cost functions $c^{j}(q)=K_{j}+q / \theta_{j}$ for $j=L, H$. Assume that $k_{H}>K_{L}$ and that $\theta_{\mathrm{H}}>\theta_{\mathrm{L}}$. So the $\mathrm{H}$ technology is more productive but requires a larger fixed cost to operate. These two technologies could be interpreted as totally independent ways of producing a particular commodity and each period firms must decide on the appropriate techniques. Alternatively, firms must decide on the number of shifts for the operation of their plants. Operating with one shift has a lower fixed cost but is less productive than operating with two shifts.

Letting $R(q)$ denote the revenues earned by producing $q$ units of output, the indirect utility for a sector 1 firm using technique $j$ is

$$
\alpha^{\alpha}(1-\alpha)^{(1-\alpha)}\left(1 / p_{2}\right)^{\alpha} R(q)-c^{j}(q)
$$

Here the price in sector 2 enters into the indirect utility gained from the revenues earned in producing good 1 . Let 
$\Phi\left(\mathrm{p}_{2}\right)=\alpha^{\alpha}(1-\alpha)^{(1-\alpha)}\left(1 / \mathrm{p}_{2}\right)^{\alpha}$

Firms in sector 2 are endowed with time which they devote to producing commodity 2. The cost of producing a unit of output is $k<1$ units of leisure. These firms also have Cobb-Douglas preferences with the budget share of sector 1 output also being $\alpha$ and the remainder of revenues spent on the nonproduced commodity. The indirect utility from producing q units of output for sector 2 firms in then given by

$\Phi\left(\mathrm{p}_{1}\right) \mathrm{R}(\mathrm{q})-\mathrm{kq}$

where $\Phi\left(p_{1}\right)$ is defined in an analogous fashion to $\Phi\left(p_{2}\right)$.

Multiple equilibria may emerge in this economy because of the presence of a choice of technique for the sector 1 firms. If all but one sector 1 firm is using technique $\mathrm{H}$, then prices in the economy will be relatively low and the remaining firm may find it worthwhile to pay the extra fixed cost to operate the more productive technology as well. Alternatively, if all but one firm is using the less productive technology, then prices in the economy will be higher and the returns to producing more for the remaining firm lower. As a consequence, it may not pay the remaining firm to utilize the more productive technology so that an equilibrium with all firms using the less productive technology can emerge as well. ${ }^{3}$

Note that an important element in this discussion is the interaction between the choice of technology and the prices of the produced goods. Since firms are consumers of the commodities produced in other sectors, their 
return to working depend on the prices of the goods they consume - this is captured by $\Phi\left(\mathrm{p}_{i}\right)$ for $i=1,2$ in the expressions above. So the gains to increased production depends on the choice of technique by other firms through the effect of technique on the price level. Since prices, as demonstrated below, are mark-ups over unit costs, the choice of technique is reflected in prices economy-wide.

To characterize the equilibrium for this economy, we focus on the game played by the firms in both sectors. The sector two firms simply select a level of output for given conjectures about the output decisions of the other firms in their sector and the output and technology choices by the sector one firms. Sector one firms select technologies and output levels given conjectures about the decisions of the other firms in the economy. In equilibrium, these conjectures are correct. Since all firms within a sector are identical, we will concentrate on symmetric equilibria within each of the two sectors. Note that, as in Hart [1982], firms are viewed as having market power in their product market but act as price takers as consumers.

The first order condition for utility maximization by a sector 2 firm is

$$
\Phi\left(p_{1}^{j}\right) R^{\prime}()=\Phi\left(p_{1}^{j}\right) \frac{E_{2} Q}{(q+Q)^{2}}=k
$$

In this expression, $q$ is the output level for this arbitrary firm and $Q$ is the output levels for other firms. $E_{2}$ is the level of expenditure on sector 2 from firms in sector 1 and the outsiders. The superscript $j$ for the sector 1 price indexes the technology used in that sector and is described below in further detail. The middle expression comes from direct computation of 
marginal revenue for the Cobb-Douglas preferences. The sector 2 output level in a symmetric Nash equilibrium given $E_{2}$ and the choice of technique $j$ in sector 1 is

$$
\mathrm{q}_{2}^{\mathrm{j}}=\frac{\Phi\left(\mathrm{p}_{1}^{\mathrm{j}}\right) \mathrm{E}_{2} \eta}{\mathrm{kF}} \quad \text { where } \eta \equiv(1-1 / \mathrm{F})
$$

Using (6) and the condition for equilibrium in sector 2 - that expenditures on sector 2 output equals revenues -- yields an expression for the sector 2 price of

$$
p_{2}^{j}=k / \eta \Phi\left(p_{1}^{j}\right)
$$

The optimization problem for sector 1 firms entails a choice of output level and a technology. To determine an equilibrium, first suppose that all firms in sector 1 use technique $L$ and select output to maximize utility. Second, solve for the equilibrium in the economy under this hypothesis about the choice of technology. Third, check to see whether or not an arbitrary firm in sector 1 would profit by deviating and producing using the $\mathrm{H}$ technology. If not, then the equilibrium with the L technology is characterized. This process can be repeated using the $H$ technology at the outset and then checking deviations to the L technology by an arbitrary firm.

The first order condition for utility maximization for an arbitrary firm in sector 1 using technology $j=H, L$ is similar to that of the sector 2 firm specified above. The differences are that $\Phi\left(p_{2}\right)$ replaces $\Phi\left(p_{1}\right)$ and that the cost function is that for technology $j$. Using the superscript $j$ to index the 
common technology, the symmetric Nash equilibrium in sector 1 given the price in sector 2 and the level of expenditures on sector $1\left(E_{1}\right)$ is

$$
\Phi\left(p_{2}^{j}\right) E_{1} \eta / F=q_{1}^{j} / \theta_{j}
$$

Using (8) and the condition for market clearing in sector 1 , the sector 1 price is then

$$
p_{1}^{j}=1 / \eta \theta_{j} \Phi\left(p_{2}^{j}\right)
$$

Together (7) and (9) determine the prices in the two sectors of the economy independently of the level of activity in the two sectors. That is, the equilibrium calculations dichotomize due to the constant marginal costs and the structure of demand. Equations (6) and (8) can then be used to determine the equilibrium levels of output in the two sectors. In solving for the quantity levels, it is necessary to determine the equilibrium levels of expenditures on each of the two sectors. From the structure of preferences and the symmetry in the model, the equilibrium level of expenditures on each sector is

$$
\mathrm{E}^{*}=(1+\alpha) \overline{\mathrm{M}} /(1-\alpha)^{2}=\mathrm{Z} \overline{\mathrm{M}}
$$

where $\bar{M}$ is the endowment of the outsiders and $Z$ is a constant. Thus, given that all firms are using technology $\mathrm{j}=\mathrm{H}, \mathrm{L},(6)-(9)$ completely characterizes the equilibrium for this economy.

The final check on these conditions is whether a given firm in sector 1 would deviate by altering both its technology and level of output. The calculations above ensure that a firm would not wish to deviate by altering 
its level of output for the given technology. Suppose that all firms in sector 1 use technology $j$, then the equilibrium level of utility for an arbitrary sector 1 firm is

$$
U_{1}(j \mid j)=\Phi\left(p_{2}^{j}\right) E^{*} / F^{2}-K_{j}
$$

This level of utility must be compared to that obtained by producing using the alternative technology,-j. If a single firm deviates and switches technology, the first order condition for utility maximization is

$$
\Phi\left(p_{2}^{j}\right) \frac{E^{*} Q^{j}}{\left(q^{-j}+Q^{j}\right)^{2}}=1 / \theta_{-j}
$$

where $q^{-j}$ is the level of output for the deviating firm.

In this condition, the level of expenditure on sector 1 and the price level in the other sector are taking as given by the firm deviating in sector 1 . The variable $\mathrm{Q}^{\mathrm{j}}$ is the level of output by the other firms in sector 1 . Since the deviation under consideration is from a proposed equilibrium, $Q^{j}$ is simply $(F-1) q_{1}^{j}$ where $q^{j}$ is given by (8). Denote by $U_{1}(-j \mid j)$ the utility of an arbitrary firm in sector 1 from using technology -j when all other firms in that sector use technology $j$. Using (11), this is

$$
U_{1}(-j \mid j)=\Phi\left(p_{2}^{j}\right) E^{*}\left(q^{-j} / q^{-j}+Q^{j}\right)^{2}-K_{-j}
$$

For $j=L$, an arbitrary sector 1 firm will not deviate and produce using the $\mathrm{H}$ technology if 


$$
\mathrm{D} \equiv \mathrm{K}_{\mathrm{H}}-\mathrm{K}_{\mathrm{L}} \geq \Phi\left(\mathrm{p}_{2}^{\mathrm{L}}\right) \mathrm{E}^{*}\left[\frac{1}{\left\{1+(\mathrm{F}-1) \mathrm{q}_{1}^{\mathrm{L}} / \mathrm{q}^{\mathrm{H}}\right\}^{2}}-\frac{1}{\mathrm{~F}^{2}}\right]
$$

The left side of this expression is the difference in fixed costs borne by a firm using the $H$ instead of the $L$ technology. The right side is the gain to the firm of using the $H$ technology rather than the $L$. The term in brackets is the gain in market share from such a deviation where $q_{1}^{L}$ is the level of output by the F-1 other firms in the candidate equilibrium and $\mathrm{q}^{\mathrm{H}}$ is the output level selected by the deviating firm given by (11). The gains in market share are then multiplied by the total level of expenditures and then deflated by the price index. Thus, when (13) holds, there will be an equilibrium described by (6) - (9) with $\mathrm{j}=\mathrm{L}$-- hereafter termed an Lequilibrium.

Note that the likelihood of there being a L-equilibrium depends on the level of expenditures $E^{*}$ which, from the analysis above, depends on the aggregate endowment of the non-produced good, $\bar{M}$. As $\bar{M}$ falls, the right side of (13) falls -- the ratio of outputs in the bracketed term is independent of $\overline{\mathrm{M}}$-- so that the condition for equilibrium is more likely to be met.

A similar condition is required for the existence of an H-equilibrium. In order for a firm not to profit by deviating from an H-equilibrium and producing with the $\mathrm{L}$ technology, it must be the case that

$$
\left.\mathrm{D} \leq \Phi\left(\mathrm{P}_{2}^{\mathrm{H}}\right) \mathrm{E}^{*}\left[\frac{1}{\mathrm{~F}^{2}}-\frac{1}{\left\{1+(\mathrm{F}-1) \mathrm{q}_{1}^{\mathrm{H}} / \mathrm{q}\right.}\right\}^{2}\right]
$$

This condition has the gains in terms of reduced fixed costs on the left side 
while the right side is the loss in real income from producing with the $L$ rather than the $\mathrm{H}$ technology. Again, the bracketed term is a measure of the difference in market share and the other two terms measure the value of the market share. Since this firm is deviating from the $H$ to the $L$ technology, it will have a lower market share than the $\mathrm{H}$ firms which is balanced by the reduction in fixed costs. This right side is an increasing function of $E^{*}$ so that for high levels of $\bar{M}$, a H-equilibrium is likely.

To determine conditions under which there will exist multiple equilibria, let $\bar{M}_{L}$ be the level of endowment such that (13) holds with equality. So if $\bar{M}<\bar{M}_{L}$ then an L-equilibrium will exist. In a similar fashion, set $\bar{M}_{H}$ so that (14) holds with equality. Then for $\bar{M}_{\mathrm{M}} \overline{\mathrm{M}}_{\mathrm{H}}$, an $\mathrm{H}$-equilibrium will exist. If $M_{L}>\bar{M}_{H}$, then there will be a range of values of $\bar{M}$ such that multiple equilibria exist. Proposition 1 indicates that multiple equilibria are a possibility in this economy if $\alpha$ is large enough.

Proposition 1: If $\alpha$ is close to 1 then $\bar{M}_{L}>\bar{M}_{H}$.

Proof: See the appendix.

The proof is relegated to the appendix because it is relatively uninformative. The intuition behind this result is simply that if firms in sector 1 produce with the $\mathrm{H}$ technology, this will induce firms in sector 1 to produce more since the gains to more output are high when the price in sector 1 is low. From (7) we see that when the sector 1 price is low, so will be the price in sector 2. From (8) this induces the firms in sector 1 to produce more and makes it more likely, from (14), that they will adopt the $\mathrm{H}$ technology. In a similar fashion, one can describe the L-equilibrium. For 
both of this equilibrium to exist for the same value of $\bar{M}$, decisions by the firms must be sufficiently responsive to the prices of consumption goods-i.e. $\alpha$ must be sufficiently large as required by the proposition.

These equilibria may also be Pareto-ranked for sufficiently large $\alpha$. Note that since commodity prices are lower in both sectors in an H-equilibrium, outsiders are certainly better off when sector 1 firms use the high fixed cost, high productivity technology. Similarly, sector 2 firms are also better off since they face lower prices for consumption goods and earn the same amount of numeraire in the two equilibria. As for sector 1 firms, they too face lower commodity prices and earn the same amount of numeraire in the two equilibria. However, they also bear the cost of the setting up the technology. These costs are outweighed by the gains of lower prices if $\alpha$ is sufficiently large.

Proposition 2 : If $\alpha$ is sufficiently large, then all agents are better off in the $\mathrm{H}$-equilibrium than in the L-equilibrium.

Proof: See the appendix.

Suppose, as suggested in the previous section, that we now view repeated play of this game in which: (i) the firms are only present for a single period and (ii) the level of endowment of the outsiders, $\bar{M}$, is an iid random variable. The assumption that the firms play only once is used to eliminate from discussion the possibility of the cooperative outcome supported as a non-cooperative equilibrium due to repeated play of the game. Note that because of the multiple equilibrium, this cooperation might develop in finite play games -- see the discussion in Benoit-Krishna [1985] and Friedman 
[1985]. The assumption that variations in $\bar{M}$ are uncorrelated is used so that the observed correlations in output are produced internally.

If the conditions in Proposition 1 hold and multiple equilibria exist, then we can employ the selection criterion discussed earlier. Suppose that $\bar{M}_{t}<\bar{M}_{H}$ so that only an L-equilibrium exists in period $t$. If $\bar{M}_{t+1}<\bar{M}_{L}$, then an L-equilibrium will exist in period $t+1$ as well. This is true even if $\overline{\mathrm{M}}_{\mathrm{t}+1}>\mathrm{M}_{\mathrm{H}} \quad-$ i.e. even if an $\mathrm{H}$-equilibrium exists as well. This is the implication of the selection criterion which states that the equilibrium will remain on a branch of the equilibrium manifold in period $t+1$ if the economy was there is period $t$. If $\bar{M}_{t+1}>\bar{M}_{L}$, then the only possibility is an $H-$ equilibrium and the economy experiences a catastrophe. In a similar way, one can describe the implications of there being an $\mathrm{H}$-equilibrium in period $t$.

The point is that this selection criterion implies correlated behavior in the economy even in the presence of iid shocks. The persistence is through the beliefs of the players of this game -- historical experience suggests a focal point to the agents. So bad economic times are likely to persist since the economy requires a large shock to $\bar{M}$ in order to move to an $H$ equilibrium. Once there, it takes a sufficiently large negative shock to $\bar{M}$ to bring the economy back to an L-equilibrium. Thus business cycle type behavior is produced without correlated shocks using this selection criterion.

\section{Conclusion}

This paper proposes a selection criterion for choosing among multiple Nash equilibria. The crux of the criterion is that agents' conjectures about the actions chosen by other agents move slowly. If the economy reaches an equilibrium in period $t$ then agents believe that the equilibrium outcome will 
be close by in period $t+l$. Actions taken based on these beliefs are correct in equilibrium. The analysis indicates that this selection criterion can produce interesting time series in which correlations are produced from serially independent shocks. As all agents in the model live for a single period and there is no "capital", these correlations are produced solely from the beliefs of the agents. The model also is helpful in understanding the catastrophic effects of large shocks to the system.

The crux of this paper is a selection hypothesis. There are numerous alternative hypotheses which can produce other outcomes: the selection of the Pareto dominant equilibrium is one such criterion. ${ }^{4}$ Evaluation of these selection hypotheses is quite difficult since the focus is on the unobservable conjectures of players in a game. One possible avenue of exploration is the construction of simple games in an experimental setting to evaluate the predictive power of these selection criteria. 
Appendix: Proof of Propositions 1 and 2

\section{Proof of Proposition 1}

Using (11), (13) and (14), the equations characterizing $\overline{\mathrm{M}}_{\mathrm{H}}$ and $\overline{\mathrm{M}}_{\mathrm{L}}$ are

(A1) $\quad \mathrm{D}=\Phi\left(\mathrm{p}_{2}^{\mathrm{L}}\right) \frac{\mathrm{KM}}{\mathrm{L}} \overline{\mathrm{F}}^{2}\left[\frac{(1+\mathrm{F}(\xi-1))^{2}}{\xi^{2}}-1\right]$

(A2)

$$
\mathrm{D}=\Phi\left(\mathrm{p}_{2}^{\mathrm{H}}\right) \frac{\mathrm{K}_{\mathrm{H}}}{\mathrm{F}^{2}}\left[1-[\xi+\mathrm{F}(1-\xi)]^{2}\right]
$$

In these expressions $\xi \equiv\left(\theta_{\mathrm{H}} / \theta_{\mathrm{L}}\right)^{\frac{3}{2}}$ and is a measure of the gains from switching technologies in terms of the productivity differentials. To show that $\bar{M}_{L}>$ $\overline{\mathrm{M}}_{\mathrm{H}}$, we need to show that

$$
\frac{\Phi\left(\mathrm{p}_{2}^{\mathrm{H}}\right)}{\Phi\left(\mathrm{p}_{2}^{\mathrm{L}}\right)} \lambda>1
$$

where $\lambda$ is the ratio of the bracketed terms is expressions (A1) and (A2). The important property of $\lambda$ is that it is independent of $\alpha$. The first term on the left side of (A3) is the key to the proposition. From the specification of preferences and the equilibrium conditions (7) and (9) for the sector specific prices,

(A4) $\frac{\Phi\left(\mathrm{p}_{2}^{\mathrm{H}}\right)}{\Phi\left(\mathrm{p}_{2}^{\mathrm{L}}\right)}=\left(\theta_{\mathrm{H}} / \theta_{\mathrm{L}}\right)^{\alpha^{2} / 1-\alpha^{2}}$

As $\alpha \rightarrow 1$, this ratio goes to $\infty$ so that (A3) will hold for $\alpha$ close to 1 . 


\section{Proof of Proposition 2}

Prices for both produced goods are lower in the H-equilibrium than in the L-equilibrium as seen from equations (7) and (9). Hence, the outsiders are better off in the H-equilibrium. Firms in sector 2 are also better off in the H-equilibrium since they face a lower price for their consumption good (sector 1 output) and earn the same amount of numeraire in the two equilibria (given by $E^{*}$ ). As for the sector 1 firms, we need to show that

(A5) $U_{1}(H \mid H)=\Phi\left(p_{2}^{H}\right) E^{*} / F^{2}-K_{H} \geq U_{1}(L \mid L)=\Phi\left(p_{2}^{L}\right) E^{*} / F^{2}-K_{L}$.

From (A5), note that the gains to being in an H-equilibrium arise from the lower prices prevailing in the economy while the gains to the L-equilibrium derive from the lower fixed cost. The existence of multiple equilibria requires that $U_{1}(H \mid H) \geq U_{1}(L \mid H)$ as given in (10) and (12). Hence a sufficient condition for sector 1 agents to prefer an $H$-equilibrium is $U_{1}(L \mid H) \geq U_{1}(L \mid L)$. That is, firms are better off using the L technology when others are using the $H$ technology than when all firms are using the L technology. Using (10), (11) and (12), this condition is

(A6) $\frac{\Phi\left(\mathrm{p}_{2}^{\mathrm{H}}\right)}{\Phi\left(\mathrm{p}_{2}^{\mathrm{L}}\right)} \geq\left[\frac{1+(\mathrm{F}-1) \mathrm{q}_{1}^{\mathrm{H}} / \mathrm{q}^{\mathrm{L}}}{\mathrm{F}}\right]^{2}$

As discussed and used in the proof of Proposition 1, the ratio of output levels $\left(\mathrm{q}^{\mathrm{H}}{ }_{1} / \mathrm{q}\right)$ is independent of $\alpha$. The left side of (A6) is increasing in $\alpha$ as noted above so that for sufficiently large $\alpha$, the inequality will hold. Hence sector 1 firms will also be better off in the H-equilibrium. 
Footnotes

1 The point is to determine a natural focal point out of the set of equilibria. The hypothesis stated here is simply that beliefs about the behavior of others are somewhat inertial in that equilibria that are close by are more compelling. As an alternative, one might assume that agents believe in cycles so that these result in equilibrium as discussed by DiamondFudenberg [1986].

2 These dynamics should be viewed as introspective as opposed to happening in real time. Otherwise, we should write down an explicit model of this adjustment process. See Howitt-McAfee [1986] for a discussion of this approach.

3 This externality in the gains of utilizing a more productive technology are also present in Shleifer [1986] though the technology is taken as given in this paper.

4 See the discussion in Harsanyi [1977] for example. 
References

Akerlof, G. and J. Yellen, "Can Small Deviations from Rationality Make Significant Differences to Economic Equilibria?" American Economic Review, 75 (1985), 708-720.

Benoit, J.P. and V. Krishna, "Finitely Repeated Games," Econometrica, 53 (1985), $905-922$.

Bulow, J., J. Geanakoplos and P. Klemperer. "Multimarket Oligopoly: Strategic Substitutes and Complements," Journal of Political Economy, 93 (1985), 488-511.

Cooper, R, and A. John. " Coordinating Coordination Failures in Keynesian Models," Cowles Foundation Working Paper \#745R, revised September 1986.

Debreu, G. "Economies with a Finite Set of Equilibria," Econometrica, 38 $(1970), 387-392$.

Diamond, P. "Aggregate Demand Management in Search Equilibrium," Journal of Political Economy, 90 (1982), 881-94.

and D. Fudenberg, "Rational Expectations Business Cycles in Search Equilibrium," mimeo, 1986.

Friedman, J., "Cooperative Equilibria in Finite Horizon Noncooperative Supergames," Journal of Economic Theory, 35 (1985) 390-398.

Furth, D. "Stability and Instability in Oligopoly;" Journal of Economic Theory, 40 (1986), 197-228.

Haltiwanger, J. and M. Waldman, "Rational Expectations and the Limits of Rationality: An Analysis of Heterogeneity," American Economic Review, 75 (1985), 326-340.

Harsanyi, J.C., "The Tracing Procedure," International Journal of Game Theory, 5 (1975), 61-94.

, Rational Behavior and Bargaining Equilibrium in Games and Social Situations, Cambridge, Cambridge University Press, 1977.

Hart, 0. "A Mode1 of Imperfect Competition with Keynesian Features," Quarterly Journal of Economics, 97 (1982), 109-38.

Heller, W. "Coordination Failure Under Complete Markets with Applications to Effective Demand," in Equilibrium Analysis. Essays in Honor of Kenneth $J$. Arrow, Volume II, edited by Walter Heller, Ross Starr and David

Starrett, Cambridge, Cambridge University Press, 1986.

Howitt, P. "Transactions Costs in the Theory of Unemployment," American Economic Review, 75 (1985), 88-101. 
and P. McAfee, "Stability of Equilibria with TradeExternalities", mimeo, 1986.

Kiyotaki, N. "Implications of Multiple Expectational Equilibria Under Monopolistic Competition," Harvard University, mimeo, 1985.

Roberts, J., "General Equilibrium Analysis of Imperfect Competition: An Illustrative Example," Stanford University, mimeo, 1984.

. "Involuntary Unemployment and Imperfect Competition:A Game Theoretic Macro Mode1," Stanford University, mimeo, 1986.

Shleifer, A., "Implementation Cycles," Journal of Political Economy, 94 (1986), $1163-1190$.

Van Damme, E., Refinements of the Nash Equilibrium Concept, Vol. 219 in Lecture Notes in Economics and Mathematical Systems ed. by M. Beckmann and W. Krelle, Springer Verlag, 1983

Varian, H., "Catastrophe Theory and the Business Cycle," Economic Inquiry, 16 (1979), 14-28. 


\section{FIGURES}

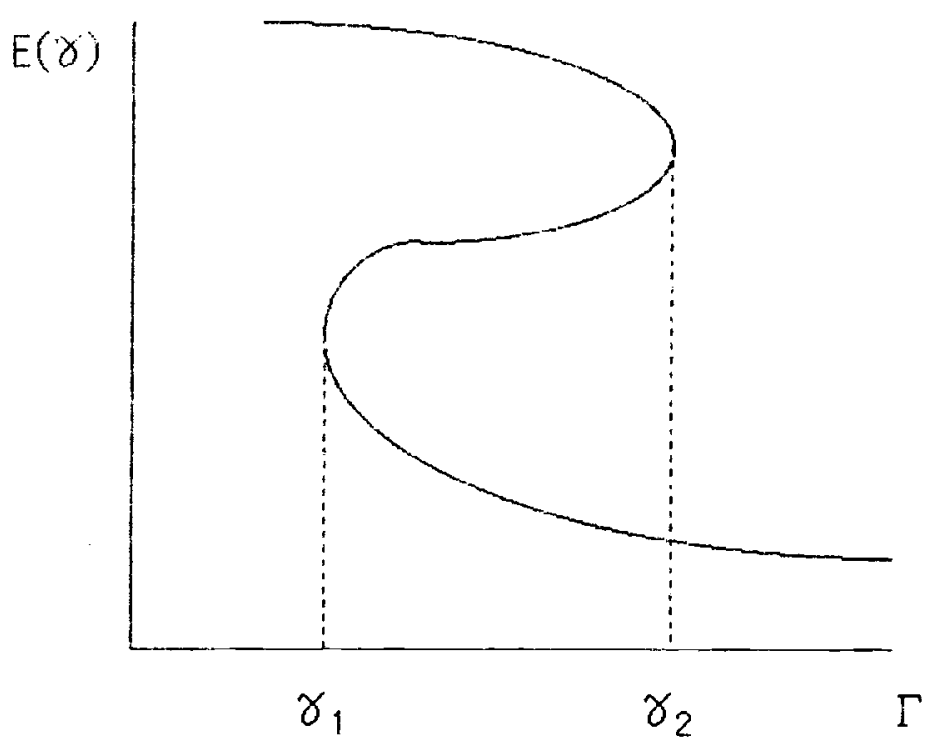

Figure 1

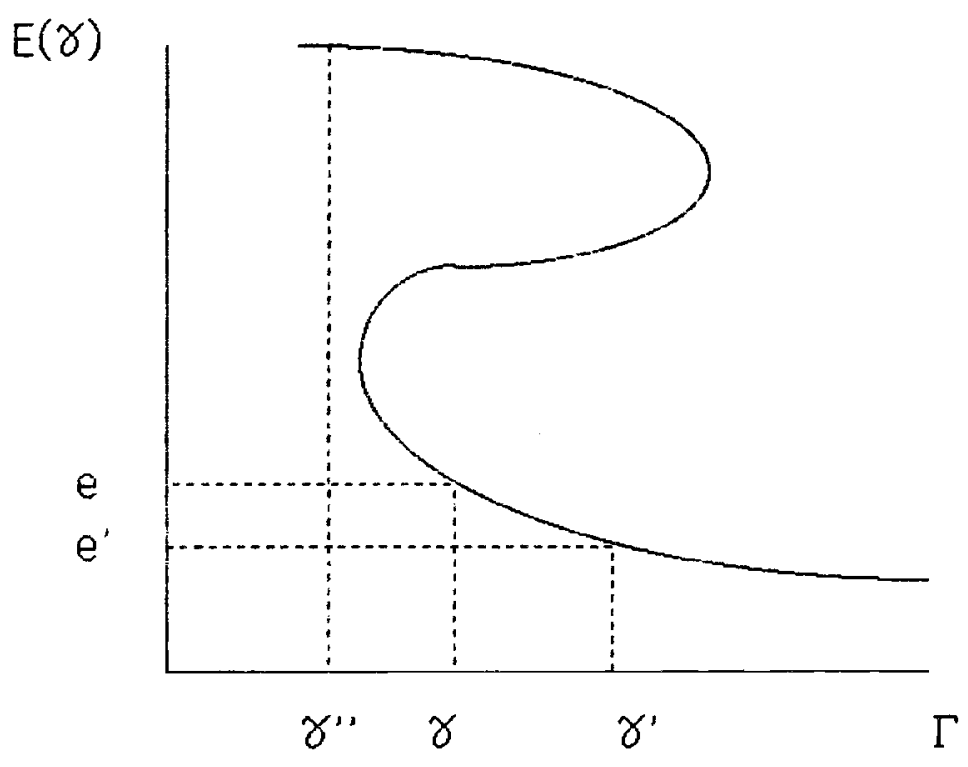

Figure 2 